with special reference to rickets and to congenital syphilis, I endeavoured to show how the increase of infantile syphilis could be accounted for merely as congenital. I showed also, by reference to the registration figures for Scotland, that most of the deaths from infantile syphilis happened in the first three months of infancy, whereas the statutory limit of vaccination in that country is six months. Dr. McVail used that argument, doubtless independently, in his book published two months after mine, and he has been duly commended in yourown columns and elsewhere for establishing a fact so well calculated to rneet the alarmist charges against vaccination. But the argument from the Scottish statistics was first established by myself; and it formed only one small part of a general exposition of the pathology of infantile syphilis as congenital syphilis. My critic in vour columns speaks of viewing a thing "in the light of present knowledge and the nature of syphilis." I commend the ninth chapter of my book on "Cowpox and Vaccinal Syphilis" to his notice, as throwing additional light on the congenital nature of infantile syphilis, and on the causes of the remarkable and hitherto inexplicable increase of the same luring the last thirty-five years. If he had read that chapter, I an sure that he would never have ascribed to me the contention that infantile syphilis was largely due to the vaccine virus, whether uncontaminated or not. I believe the mistake primarily arose among the anti-vaccinist writers, who imagined, from the context of my chapter on the increase of infantile syphilis, that $I$ was going to prophesy in favour of their own alarmist teaching on that point, and read no farther. Is it possible that an editorial writer in your columns can have been taking statements at secondhand from the antivaccinists?

I nust not occupy your space to traverse your editorial criticism in general. But I should like to remark that the "spontaneous" origin of cow-pox is the usual teaching (see especially Clay ton's "Veterinary Evidence from Gloucestershire," in Beduoes" "Contributions to Physical and Medical Knowledge,"Bristol, 1799; and Ceely's "Classical Memoirs," 1840-42). Further, the doctrine that so-called vaccinal syphilis is not due to contamination of the lymph with the venereal virus was ably defended by an editorial writer, evidently of great experience and sound judgment, in your own leading columns on May 6th, 1871, on the occasion of Mr. Hutchinson bringing forward his first series of cases. The only point which he did not adequately deal with was the occurrence of a few cases which did have secondary or constitutional symptoms, side by side with a much larger number where there was only the primary sore, both in the London group of cases, infected from a common source, and in the great epidemic among infants in the Morbihan in 1866; and that point, which he did not grapple with, is, I think, the crux of the whole matter. My last remark is to deprecate the feeling of amazement with which readers of my book on Cow-pox are said by you to regard the inclusion of its argument in a standard work of reference. The book was published thirteen months before the article, and was designed to show by a full statement of facts the incorrectness of the Jennerian doctrine that cow-pox is "small-pox of the cow." The upholders of that doctrine have had an ample opportunity of answering my indictment, but they have not availed themselves of it. Am I not entitled to say, therefore, that judgment has gone against them by default?

$$
\text { I am, Sirs, your obedient servant, }
$$

Nor. 26th, 1888

C. Creighton.

* * We gladly accept Dr. Creighton's disclaimer of views, which seemed too fanciful for him to have promulgated intentionally. At the same time, we fail to see the force of the reasoning whereby he claims for "vaccinal syphilis" an origin independent of "venereal syphilis," and cannot admit that he is wholly free from the charge of laying at the loor of the former the responsibility of a certain proportion of the increasing mortality from infantile syphilis. We have referred to the chapter he mentions, and would direct his attention to his own arguments on $\mathrm{pp} .153$ to 156 , which surely justified our criticism. It appears, however, that we have misunderstood him, and in that case, when he speaks of vaccinal syphilis as a return to the primary cow-pox, and this as being "on all fours with venereal pox," he did not mean that vaccination could induce infantile syphilis.ED. L.

\section{MENSTRUATION AND THE OVARIES.}

\section{To the Editors of THE LANCET.}

Sres,-Drelincourt collected the theories of generation, and found them to be 262. We seem threatened with an equal number on the subject of menstruation. Every year produces a new hypothesis. The two most recent are the Uterine and the Fallopian, propagated by Dr. Johnstone and Mr. Tait. The old ovarian theory, however, I believe, still remains unshaken, and it must not be confounded with the ovular theory, the holders of which maintain that menstruation is dependent upon and synchxonous with the ripening and escape of an ovum from the ovary. The ovarian theory is that menstruation primarily depends on the existence of an ovary, and the facts upon which this belief rests are-(1) that when the ovaries are congenitally absent menstruation is also wanting; (2) that when the ovaries are removed early in life the same result is observed; (3) that when the ovaries are removed after puberty menstruation generally ceases; (4) that all the secondary sexual characters in the female are dominated by the ovary, and menstruation is one of these. The prime and all-important act of the sexual apparatus is the production of ora in the female and spermatozoa in the male. The ovaries and testicles furnish the generative elements essential to reproduction. The rest of the reproductive organs and their functions are subservient. Menstruation, nidation, the sexual appetite, the growth of hair on the face and pubes, the change of voice, the development of the pelvis and breasts, \&c., are all dependent upon the presence of an ovary or testicle for their existence; and they are not essential to the acts of impregnation and gestation.

The connexion of the ovaries with menstruation was pointed out by Roederer in 1779 . He noticed their enlargement at puberty and their atrophy at the menopause; and this leads us to the consideration of the ovular theory, which has a certain amount of truth in it. Menstruation without doubt appears during the period of life when the ovarian function of ovulation is most active; but it has not been proved that the menstrual flow and the escape of an ovum have any causal relation determining their occurrence at the same tine.

The uterine theory of menstruation advanced by Dr. Johnstone is difficult to accept. He maintains that the uterus is "an independent organ," and performs its menstrual function without any aid from the appendages; but the Fallopian hypothesis is still more impossible to believe. Although propounded in its "divine simplicity" by Mr. Tait, it appears utterly untenable and quite destitute of any scientific foundation. The reasons why he believes the Fallopian tubes to be the "starting point" of menstruation are: 1. Pain when the tubes are occluded. 2. The first appearance of menstrual finid in the tubes. 3. The continuance of menstruation after removal of the ovaries. 4. The arrest of menstruation after removal of the tubes. The conclusions he draws from these reasons are: "That the old statement that the ovaries rule the function of menstruation is not based on fact" and that "the tubes have more to do with menstruation than the ovaries." To my mind, these deductions cannot be logically arrived at from the propositions he has enumerated, even granting them all to be true. If pain in an occluded tube confirms the Fallopian theory, pain in an occluded uters must equally substantiate the uterine theory. The point at which the menstrual fluid first appears might also be used in support of both hypotheses; but the site at which an excretion is first seen has not necessarily any connexion with its primal determining cause. No one would think of attributing the secretion of milk to the influence of the lacteal ducts. It is quite possible that the extirpation of the Fallopian tubes may cause permanent amenorrhoea, but this is probably not so much due to the absence of the tubes as to the injury inflicted on the vessels and nerves of the ovaries. Mr. Tait also urges against the ovarian theory that the removal of the ovaries does not arrest menstruation. Now here we have arrived at an important part of the subject, and one which should always be borne in mind. It seems to be a fact that after puberty the system receives an impression (ovarian?) which enables it to continue and maintain, although in a modified form, the secondary sexual functions, even after the removal of the organs upon which they primarily depended. The extirpation of the ovaries and testicles before and 
after puberty has widely different results upon the individual. If done before puberty, he or she becones a sort of neutral being between man and woman. If performed after puberty, the sexual characteristics are to a great extent maintained. And here $I$ will present $M r$. Tait with the only feasible argument in favour of his Fallopian theory with which I am acquainted. It is drawn from analogy. If in castration the epididymis be left, the result is an imperfect eunuch. Erection, copulation, and ejaculation of fluid still remain possible. Now, although the parovarium is the analogue of the epididymis, the Fallopian tube is the excretory duct of the ovary as the epididymis is part of that of the testicle. It is just possible, therefore, that spaying may not be complete without removing at least a portion of the tube with the ovary. But, even if we consent to endow the tube with some ovarian attributes, it is impossible to believe that the secondary sexual manifestations can be due to its sole influence. After exhausting his arguments for the Fallopian theory, Mr. Tait makes the following extraordinary statement: "Menstruation is nidation." Now, as I was the first to employ the word " nidation," I may perhaps be considered a competent authority as to its meaning. The definition I gave in 1874 was this: "The act of nidation consists of the periodical development of the lining of the interior of the body of the uterus." Nidation is a function of the uterus separate from menstruation, and has nothing to do with the Fallopian tube. Denidation takes place during menstruation, and the casting off of the nidal decidua probably bears the same relation to the catamenia as the sherding of the gravidal decidua does to the lochia Perhaps Mr. Tait will explain what he means when he says "menstruation is nidation."

It is to be hoped that the writers of text-books will, as Mr. Tait wishes, give this subject much serious study before they promulgate, with the mamisterial confidence of its author, the groundless and unscientific Fallopian theory of menstruation.- $\mathrm{I}$ am, Sirs, yours truly,

Upper Wimpole-street, W., Nov. $1888 . \quad$ J AMES H. Avelir G.

\section{To the Editors of THE LANCET.}

SIRS,-The facts brought forward by Mr. Lawson Tait in your last issue conclusively show that the monthly flow in woman may take place independently of the ovaries, and strongly suggest that it is largely dependent upon a nervous structure situated in or near the Fallopian tubes. That the menstrual rhythm is initiated by a nervous rhythm, I, for one, have little doubt. Just as there is a rhythmically pulsating respiratory and cardiac centre, so likewise is there, probably, a rhythmically pulsating sexual centre. What may be the position of this hypothetical centre I do not profess to say, but I venture to suggest that it furnishes fibres both to the ovaries and uterus, those to the latter passing for the most part along the Fallopian tubes, but sone few to the uterus directly. This hypothesis explains all the facts of the case: (1) that the periodic flow continues after the removal of the ovaries; (2) that it generally ceases when the tubes have been removed; (3) that in rare cases it continues after both ovaries and tubes have been removed.

I have assumed, it will be observed, that ovulation is an essential part of the menstrual rhythm. 'Thus was I taught, and thus I must continue to believe until the most indisputable arguments to the contrary can be advanced. The view that ovulation only recurs two or three times a year in woman must excite a thrill of surprise in all those who hear it for the first time. I am aware that most animal organisms display redundancies. These are the necessary accompaniments of organic evolution. Such redundancies of structure are, however, in very large measure functionless They take no part in the general economy of the organism. Now, of all redundancies, this presumed menstrual redundancy is surely the most extraordinary. Can it be possible that the human female organism is such a strange bungler as to put itself to the trouble of "building and furnishing" a nest every month for the reception of the human embryo, withont at the same time providing a potential occupant in the slrape of a fertilisable ovum? The reply may be made that there is a redundancy, whether ovulation be monthly or not, seeing that menstruation is often to no purpose on account of non-impregnation. Let it be remembered, however, that in the ordinary course of nature the ovum would very seldom escape unimpregnated, and under these circumstances the woman would practically never suffer a monthly loss of blood, for her whole period of reproductive life would be occupied in gestation and lactation, during which times menstruation does not ordinarily oceur.

Nov. 26th, 1888. I am, Sirs, yours faithfully, HARRY CAMPBELL, M.D.

\section{THE LATE MR. BORLASE CHILDS. To the Editors of THE LANCET.}

Sirs, - In the notice of the late Mr. Borlase Childs, reference is very properly made to his excellence as $a$ lithotomist amongst his other surgical qualifications. He was perhaps as remarkable for his ready resource and de. cision in a difficulty as he was for his manual skill, and as an illustration of this fact permit me to relate a circumstance connected with an operation of lithotomy which I witnessed, and to which I have often referred. Some thirty years ago a well-known surgeon requested Mr. Childs, the late Mr. Gay, inyself, and one or two others to be present and assist him in an operation for stone on a boy in private. After anasthesia liad been produced the surgeon in question proceeded to sound the patient, but on making prolonged and careful search he could not feel the stone. The sound was then handed to each of us in turn, but the only person who said he could detect it was Mr. Childs. A consultation being held, it was agreed that the intending operator should follow the rule under such circunstances, and rot attempt the lithotomy ; but as Mr. Childs averred that he felt the stone, the offer was made to lim that he should perform the operation. He at once decided that he would do so; the patient was placed in position, the bladder was skilfully opened, and a stone extracted. This was a bold course of action, and, considering the errors which have been committed in connexion with the diagnosis of stone in children some may say it was rash; but, knowing the man well, not only was not surprised, but admired his decision, his confidence in himself, and with others present congratulated him on the accuracy of his judgment.

I am, Sirs, yours obediently

Wimpole-street, Nor. 1888.

HENRY SMITH.

\section{"SANITARY ADMINISTRATION AT BRIXHAMI.}

To the Editors of THE LANCET.

SIRs,-My attention has been called to an annotation in your issue of Nov. 24th, headed "Sanitary Administra. tion at Brixham," in the course of which you proceed to sererely censure the sanitary administration of Paignton, on apparently no better authority than the "hare-brained chatter" of some "irresponsible" member of the Brixhan local board, who is reported to have stated that "in Paignton last year, when typhoid and diphtheria were there, it was kept quiet." Then, Sirs, you go on to remark that " these circumstances create a grave scandal," and th at you " trust they will become known to the authorilies at Wlitehall, and that both Brixham and Paisnton will be inspected, and some steps taken to prevent the occurrence of these epidemics." The slightest investigation would have shown you that such remarks with regard to Paignton are entirely uncalled for, and constitute a gross libel on the town. "Last year" there was no case of diphtheria in Paignton, and no typhoid fever, epidemic or sporadic; there were only four deaths from zymotic disease during the year, all due to scarlatina-one occurring in January, one in July, and two in December, the latter occurring in the sanitary district, but at a distance of three miles from the town; the death-rate from all causes for the whole rear (1887) was only $12 \cdot 7$ per 1000 on an estimated popula. tion of 6500 . This year there have been six cases of diphtheria, two in piay in the same house, and four in August, two of which were fatal. All the cases were at once reported to the medical officer of health, and the exciting cause of the disease was in each case promptiy discovered and removed, and successful measures taken to prevent any spread of the disorder. A full report as to these cases was made to the urban sanitary authority, the local board, at their meetings on the first Mondays in June 